\title{
Institutional hypertension control in Malaysia: a multicenter study focusing on gender and cardiovascular risk factor profile difference
}

\author{
Maskon Oteh ${ }^{1}$, Shah Mohd Shah Azarisman ${ }^{2}$, Syazril Adnan Azreen ${ }^{3}$, Ab Rahman Jamaluddin ${ }^{2}$, \\ Abdullah Aszrin ${ }^{2}$, Chih Kuan Ting ${ }^{1}$ and Ismail Shaiful Bahri ${ }^{3}$
}

The prevalence of hypertension in Malaysia is alarmingly high. The National Survey in 2006 showed $43 \%$ of people aged $\geqslant 30$ had hypertension and among treated patients, only $26 \%$ reached the target blood pressure (BP) of $<140 / 90 \mathrm{~mm} \mathrm{Hg}$. We evaluated BP control in tertiary institutions in Malaysia and the difference in hypertension control between genders and within specific cardiovascular risk factor groups. This cross-sectional study aimed at determining BP control among hypertensive patients attending three specialist institutions in Malaysia, located in Kuala Lumpur, Kuantan and Kota Bharu. A total of 950 patients with known hypertension for at least 6 months were recruited between January 2007 and July 2008. There were more males $(n=548,57.7 \%)$ with a mean age of $60.3 \pm 10.5$ ( \pm s.d.) years. The mean systolic BP (SBP) and diastolic BP were $138.8 \pm 20.3 \mathrm{~mm} \mathrm{Hg}$ and $79.6 \pm 11.3 \mathrm{~mm} \mathrm{Hg}$, respectively. In total, $48.5 \%$ of all the patients had good BP control $(<140 / 90 \mathrm{~mm} \mathrm{Hg}$ ). Males had better SBP control compared with female (SBP: $135.9 \pm 18.7 \mathrm{vs} .142 .8 \pm 21.7 \mathrm{~mm} \mathrm{Hg}$, $P<0.001$ ). Overall, $54.6 \%$ of the patients had ischemic heart disease (IHD), $24.2 \%$ had undergone coronary revascularization, $50.1 \%$ were diabetic, $68.6 \%$ hyperlipidemic, $17.3 \%$ smokers and $27.5 \%$ had renal impairment. Males and small numbers of antihypertensives used were independently associated with better treatment outcome. In summary, our data reveal a poorer BP control, secondary to higher SBP levels in women. Moreover, the gender difference is more pronounced in patients with concomitant diabetes mellitus, renal impairment and IHD.

Hypertension Research (2011) 34, 319-324; doi:10.1038/hr.2010.239; published online 9 December 2010

Keywords: control; gender; prevalence

\section{INTRODUCTION}

Arterial hypertension is the leading cause of cardiovascular mortality and morbidity worldwide. It contributes to half of the coronary artery disease and two-thirds of the cerebrovascular disease burden. ${ }^{1}$ In Malaysia, hypertension prevalence is seeing a steep rise. Over the past three decades, hypertension prevalence has increased from $14.4 \%$ in 1986 to $29.9 \%$ in 1996 and, most recently, to $42.6 \%$ in the third National Health and Morbidity Survey (NHMS III) conducted in $2006 .^{2,3}$ Of those who were on treatment, only $26.3 \%$ achieved the treatment targets. ${ }^{3}$ This worrying trend has outpaced global prevalence of $26.4 \%$ in 2000 and is contrary to the US, for example, where there has been improvements in overall hypertension prevalence and control. ${ }^{4,5}$

The global increase in hypertension-related disease is accelerating in women. ${ }^{6}$ Although the meta-analysis by Turnbull et al. points to comparable blood pressure (BP) control levels for both men and women, other studies have shown poorer control and worse outcomes in women. ${ }^{7-9}$ This is seen in the increased early mortality and poorer outcomes in women with coronary artery diseases. ${ }^{10,11}$ In Malaysia, the NHMS III household survey found that female hypertensives had higher mean systolic BP (SBP) levels and poorer control level compared with men across all major ethnic groups. This difference is perplexing, as women tended to be more aware of their hypertension status. ${ }^{2}$ Therefore, there is an urgent need to gauge the level of hypertension control among women under follow-up in healthcare institutions to see whether the trend continues.

The objective of this study is to determine the BP control among patients from three different tertiary referral centers in Malaysia. It is also aimed at gauging the level of BP control differences between the genders and the different modifiable risk factors (RFs) associated with coronary artery disease. This study represents the first multicenter study of hypertension control in Malaysia and would add a different perspective to the published data from the NHMS.

\footnotetext{
${ }^{1}$ UKM Medical Center Kuala Lumpur, Kota Bharu, Malaysia; ${ }^{2}$ Faculty of Medicine, International Islamic University Malaysia, Kuantan, Malaysia and ${ }^{3}$ University of Science Malaysia, Kota Bharu, Malaysia

Correspondence: Dr SMS Azarisman, Associate Professor and Consultant Physician/Cardiologist, Deputy Dean (Academic), Faculty of Medicine, International Islamic University Malaysia, Jalan Sultan Ahmad Shah, Kuantan 25200, Pahang Darul Makmur, Malaysia.

E-mail: risman1973@hotmail.com

Received 12 July 2010; revised 14 August 2010; accepted 6 September 2010; published online 9 December 2010
} 


\section{METHODS}

The study was conducted in three tertiary referral centers, namely the Cardiology outpatient clinics at UKM Medical Center, Kuala Lumpur; Hospital Tengku Ampuan Afzan, Kuantan; and the Medical outpatient clinic at Hospital University of Science Malaysia, Kota Bharu. UKM Medical Center is located in the southeast corner of Kuala Lumpur and caters predominantly for the urban population. Kuantan is the capital of the east-coast Peninsular Malaysian state of Pahang, whereas Kota Bharu is the capital of the northeast-coast Peninsular Malaysian state of Kelantan. Both Kuantan and Kota Bharu serve a population of 1.5-2 million people, have predominantly agrarian economies and the majority of the population is looked after in the public health care sector.

A total of 950 patients with hypertension attending the aforementioned clinics, who satisfied the inclusion criteria, were enrolled in a cross-sectional study between January 2007 and July 2008. The study protocol was approved by the medical research and ethics committees of each institution independently, and written informed consents were obtained from the subjects. The study was conducted in concordance with the Code of Ethics of the World Medical Association (Declaration of Helsinki, 1964 and Declaration of Tokyo, 1975, as revised in 1983).

All patients who were Malaysian citizens, aged above or equal to 30 years, had been diagnosed and were on treatment for hypertension for at least 6 months, were included in the study. Patients who were pregnant, newly diagnosed hypertensives, defaulted treatment for more than 6 months, critically ill, had mental health problems or difficulty in communication were excluded.

Simple demographic data was recorded, the antihypertensive medications were noted and the cardiovascular risk profiles were identified. Patients with concomitant medical illnesses were also identified. Two-sitting SBP and diastolic $\mathrm{BP}(\mathrm{DBP})$ readings were taken manually $3 \mathrm{~min}$ apart using a standard mercury sphygmomanometer (cuff size $12.5 \times 40 \mathrm{~cm}$ ) by the attending physician. The SBP and DBP levels were read to the nearest $2 \mathrm{~mm} \mathrm{Hg}$, and the appearance (phase 1) and disappearance (phase 5) of Korotkoff's sounds were the criteria for SBP and DBP. Controlled BP was defined as $<140 / 90 \mathrm{~mm} \mathrm{Hg}$ and $<130 / 80 \mathrm{~mm} \mathrm{Hg}$ for those with concurrent diabetes, and $<125 / 75 \mathrm{~mm} \mathrm{Hg}$ for those with concurrent renal impairment. ${ }^{12}$

\section{Statistical analysis}

Data for continuous, closely symmetrical variables were analyzed using standard descriptive methods to estimate means and s.d.. The comparison between means was determined using the independent sample $t$-test. Discrete data and proportions are compared using $\chi^{2}$ test, with the level of statistical significance set at $P<0.05$. Logistic regressions to predict treatment outcome were performed giving adjusted odds ratios for gender, age, number of antihypertensives used, diabetes status, coronary artery disease status, revascularization, chronic renal failure, smoking and hyperlipidemia. All statistical analyses were performed with the statistical software package for the social sciences, SPSS (Version 12, SPSS, Chicago, IL USA).

\section{RESULTS}

A total of 950 patients with hypertension were enrolled and of these, $57.7 \%$ (548/950) were males and the mean SBP and DBPlevels were $138.83 \pm 20.3$ and $79.65 \pm 11.39 \mathrm{~mm} \mathrm{Hg}$, respectively. Table 1 summarizes the demographical characteristics and RF profile of patients.

Table 1 also demonstrates that the degree of $\mathrm{BP}$ control ranges between $45.1 \%$ in UKM Medical Center (HUKM) and $54.0 \%$ in Hospital University of Science Malaysia, with an overall control level of $48.5 \%$. Interestingly, $54.6 \%$ (519/950) of patients had ischemic heart disease (IHD) but only $23.9 \%$ had had revascularization procedures either via coronary artery bypass graft surgery or percutaneous coronary intervention.

When we looked into the gender differences in terms of the level of BP control, we found that there was significantly poorer level of hypertension control in females across all three centers and across the major cardiovascular RF profiles. This is illustrated by the consistently higher mean values of SBP in Figures 1 and 2.

Table 2 and Figure 3 illustrate the mean SBP difference between males and females by the number of antihypertensives utilized. Table 2 details the mean age, SBP and DBP as they increase with the number of antihypertensives utilized. Figure 3 shows a wide divergence between 1 and 3 antihypertensives, which narrows significantly with 4 or 5 antihypertensives used and a progressively higher mean SBP with increasing number of antihypertensives.

Table 3 illustrates the differences in hypertension control level between the genders. In all, $53.5 \%$ of the males attained the desired BP level of $<140 / 90 \mathrm{~mm} \mathrm{Hg}$ compared with only $41.8 \%$ of the

Table 1 Demographic and RF profile of patients screened at respective centers (HUKM, HTAA and HUSM)

\begin{tabular}{|c|c|c|c|c|}
\hline & Total sample, $\mathrm{n}=950(b, \mathrm{n}=658)$ & HUKM, $\mathrm{n}=319$ (33.6\%) & HTAA, $\mathrm{n}=331$ (34.8\%) & HUSM, $\mathrm{n}=300(31.6 \%)$ \\
\hline Age (years) & $61.70 \pm 10.29^{a}$ & $60.08 \pm 11.00^{a}$ & $60.84 \pm 10.96^{a}$ & $60.87 \pm 10.76^{a}$ \\
\hline \multicolumn{5}{|l|}{ Gender } \\
\hline Males & $548(57.7 \%)$ & $184(57.7 \%)$ & $214(64.6 \%)$ & $150(50.0 \%)$ \\
\hline Females & $402(42.3 \%)$ & $135(42.3 \%)$ & $117(35.4 \%)$ & $150(50.0 \%)$ \\
\hline SBP (mm Hg) & $138.83 \pm 20.3^{a}$ & $141.42 \pm 20.32^{a}$ & $139.49 \pm 20.60^{a}$ & $135.36 \pm 19.52^{a}$ \\
\hline $\mathrm{DBP}(\mathrm{mm} \mathrm{Hg})$ & $79.65 \pm 11.39^{a}$ & $78.61 \pm 13.02^{a}$ & $81.53 \pm 10.57^{a}$ & $78.67 \pm 10.08^{a}$ \\
\hline No. of antihypertensives & $2.20 \pm 0.92^{a}$ & $2.24 \pm 0.94^{a}$ & $2.24 \pm 0.88^{a}$ & $2.12 \pm 0.95^{a}$ \\
\hline Percentage with controlled BP & $461(48.5 \%)^{b}$ & $144(45.1 \%)^{\mathrm{b}}$ & $155(46.8 \%)^{\mathrm{b}}$ & $162(54.0 \%)^{\mathrm{b}}$ \\
\hline \multicolumn{5}{|l|}{ RF profiles } \\
\hline Diabetes mellitus & $476(50.1 \%)$ & $173(54.2 \%)$ & $150(45.3 \%)$ & $153(51.0 \%)$ \\
\hline Ischemic heart disease & $519(54.6 \%)$ & $206(64.6 \%)$ & $243(73.4 \%)$ & $70(23.3 \%)$ \\
\hline Revascularization & $157(23.9 \%)^{c}$ & $78(24.5 \%)$ & 79 (23.9\%) & NA \\
\hline Renal impairment & $261(27.5 \%)$ & $85(26.6 \%)$ & $65(19.6 \%)$ & $111(37.0 \%)$ \\
\hline Smoking & $114(17.3 \%)^{c}$ & $47(14.7 \%)$ & $67(20.2 \%)$ & NA \\
\hline Hyperlipidemia & $652(68.6 \%)$ & $245(76.8 \%)$ & $233(70.4 \%)$ & $174(58.0 \%)$ \\
\hline
\end{tabular}




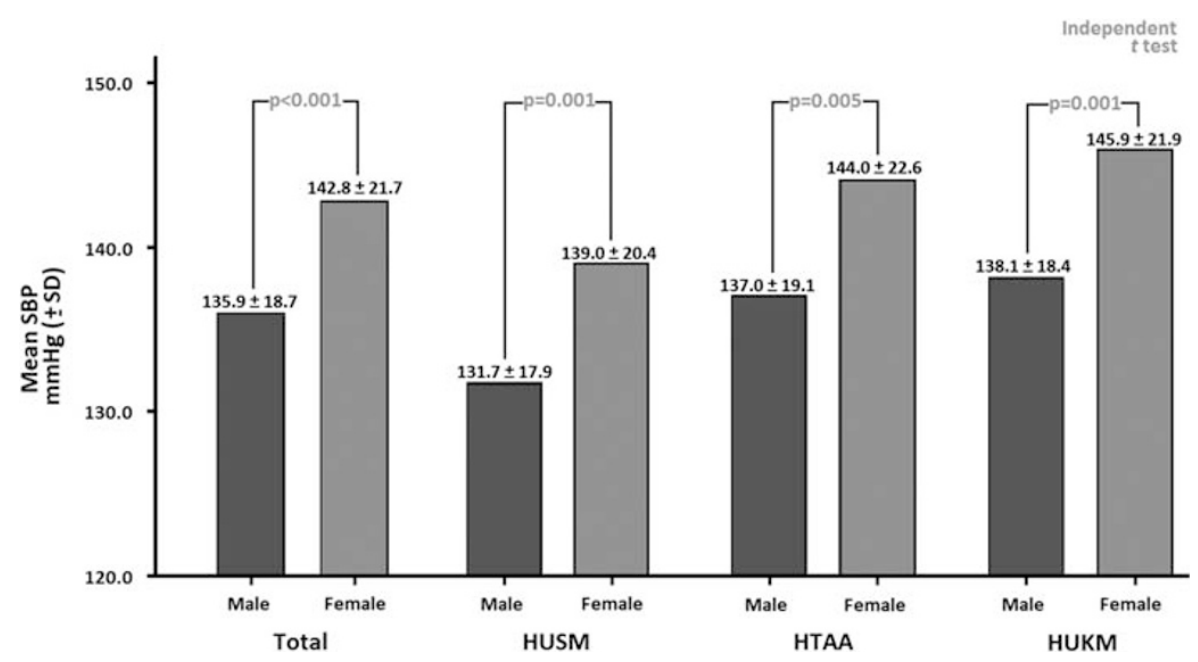

Figure 1 Mean systolic blood pressure (SBP) across all centers showed significantly higher blood pressure levels in females. A full color version of this figure is available at the Hypertension Research journal online.

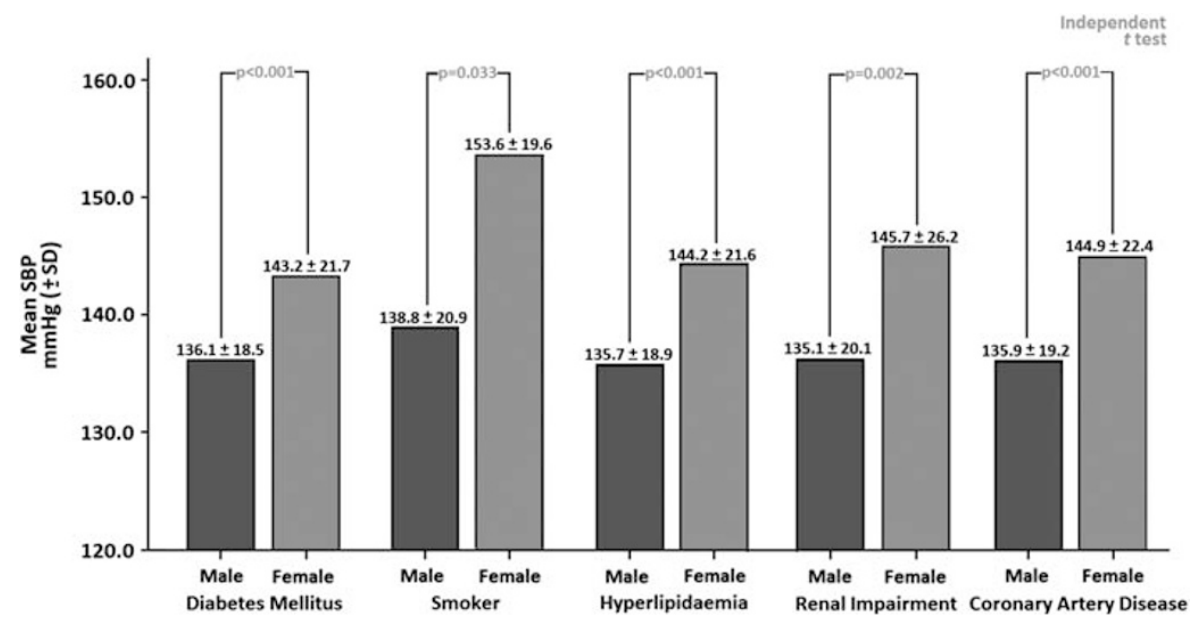

Figure 2 Mean systolic blood pressure (SBP) across all risk factors showed significantly higher blood pressure levels in females. A full color version of this figure is available at the Hypertension Research journal online.

Table 2 Mean values of age, SBP and DBP of 935 hypertensives by number of antihypertensives

\begin{tabular}{lccccc}
\hline & \multicolumn{5}{c}{ No. of antihypertensives } \\
\cline { 2 - 6 } & 1 & 2 & 3 & 4 & 5 \\
Variables & $(\mathrm{n}=217)$ & $(\mathrm{n}=387)$ & $(\mathrm{n}=256)$ & $(\mathrm{n}=65)$ & $(\mathrm{n}=10)$ \\
\hline Age & $60.1 \pm 11.4$ & $59.9 \pm 11.0^{\mathrm{a}}$ & $62.5 \pm 9.7$ & $61.5 \pm 10.2$ & $64.2 \pm 13.2$ \\
SBP & $134.5 \pm 18.2$ & $137.9 \pm 18.7^{a}$ & $142.4 \pm 22.2$ & $142.2 \pm 23.8$ & $155.1 \pm 29.6$ \\
DBP & $79.0 \pm 10.4$ & $79.6 \pm 11.3$ & $80.2 \pm 11.7$ & $79.6 \pm 13.4$ & $84.2 \pm 14.4$ \\
\hline
\end{tabular}

Abbreviations: DBP, diastolic blood pressure; SBP, systolic blood pressure.

${ }^{a} P<0.05$ vs. three antihypertensives by independent sample $t$-test.

females. It also demonstrates that significantly higher proportions of males smoke, have IHD and subsequently revascularized.

When we scrutinized the data for patients with good vs. poor BP controls, the level of control in patients with concomitant diabetes and renal impairment was far less compared with the rest of the patients at only 18.9 and $18.4 \%$, respectively (Table 4 ). Furthermore, when we looked at the difference in terms of BP control between the genders

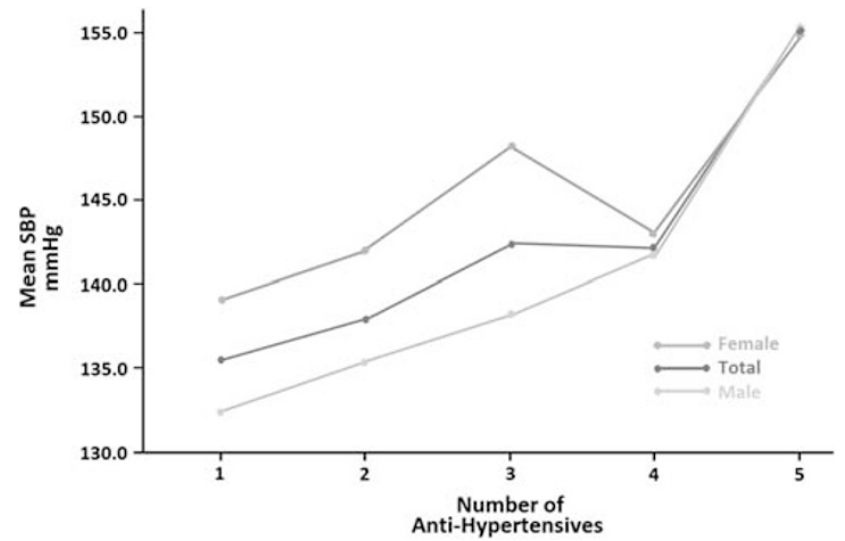

Figure 3 Mean systolic blood pressure (SBP) difference between genders by the number of antihypertensives used. A full color version of this figure is available at the Hypertension Research journal online.

within the different cardiovascular RF subgroups, there was a statistically significant lower level of BP control in females across all subgroups (Table 5). 
Table 3 Comparison between male and female hypertensives

\begin{tabular}{|c|c|c|c|c|}
\hline & $\begin{array}{c}\text { Total } \\
\text { sample, } \\
\mathrm{n}=950 \\
(b, \mathrm{n}=658)\end{array}$ & $\begin{array}{c}\text { Males, } \\
\mathrm{n}=548 \\
(57.7 \%) \\
(c, \mathrm{n}=398)\end{array}$ & $\begin{array}{c}\text { Females, } \\
\mathrm{n}=402 \\
(42.3 \%) \\
(d, \mathrm{n}=252)\end{array}$ & P-value \\
\hline Age (years) & $61.7 \pm 10.3^{a}$ & $60.3 \pm 10.5^{a}$ & $61.6 \pm 11.0^{\mathrm{a}}$ & $0.065^{b}$ \\
\hline $\mathrm{SBP}(\mathrm{mm} \mathrm{Hg})$ & $138.8 \pm 20.3^{a}$ & $135.9 \pm 18.7^{a}$ & $142.8 \pm 21.7^{a}$ & $<0.001^{b}$ \\
\hline $\mathrm{DBP}(\mathrm{mm} \mathrm{Hg})$ & $79.6 \pm 11.3^{a}$ & $79.7 \pm 11.8^{\mathrm{a}}$ & $79.6 \pm 10.7^{a}$ & $0.884^{b}$ \\
\hline No. of antihypertensives & $2.2 \pm 0.9^{a}$ & $2.2 \pm 0.9^{\mathrm{a}}$ & $2.1 \pm 0.9^{\mathrm{a}}$ & $0.305^{b}$ \\
\hline $\begin{array}{l}\text { Percentage with } \\
\text { controlled BP }\end{array}$ & 461 (48.5\%) & 293 (53.5\%) & $168(41.8 \%)$ & $<0.001^{c}$ \\
\hline \multicolumn{5}{|l|}{ RF profiles } \\
\hline Diabetes Mellitus & $476(50.1 \%)$ & $268(48.9 \%)$ & $208(51.7 \%)$ & $0.388^{c}$ \\
\hline Ischemic heart disease & $519(54.6 \%)$ & $346(63.1 \%)$ & $173(43.0 \%)$ & $<0.001^{\circ}$ \\
\hline Revascularization & $157(23.9 \%)^{d}$ & $122(30.7 \%)^{e}$ & $35(13.9 \%)^{f}$ & $<0.001^{\mathrm{c}}$ \\
\hline Renal impairment & $261(27.5 \%)$ & $160(29.2 \%)$ & $101(25.1 \%)$ & $0.229^{c}$ \\
\hline Smoking & $114(17.3 \%)^{d}$ & $104(26.1 \%)^{\mathrm{e}}$ & $10(3.9 \%)^{f}$ & $<0.001^{c}$ \\
\hline Hyperlipidemia & $652(68.6 \%)$ & $389(70.9 \%)$ & $263(65.4 \%)$ & $0.053^{c}$ \\
\hline \multicolumn{5}{|l|}{ Type of antihypertensives } \\
\hline ACEI/ARB & $673(70.8 \%)$ & $398(72.6 \%)$ & $275(68.4 \%)$ & $0.09^{c}$ \\
\hline$\beta$-Antagonist & $552(58.1 \%)$ & $342(62.4 \%)$ & $210(52.2 \%)$ & $0.001^{c}$ \\
\hline Diuretics & $300(31.6 \%)$ & $168(30.7 \%)$ & $132(32.8 \%)$ & $0.260^{\circ}$ \\
\hline $\mathrm{CCB}$ & $441(46.4 \%)$ & $248(45.3 \%)$ & $193(48.0 \%)$ & $0.219^{c}$ \\
\hline$\alpha$-Antagonist & $50(5.3 \%)$ & $28(5.1 \%)$ & $22(5.5 \%)$ & $0.457^{c}$ \\
\hline Antiplatelets & $497(76.5 \%)$ & $320(80.4 \%)$ & $177(70.2 \%)$ & $0.002^{c}$ \\
\hline Statins & $540(83.1 \%)$ & $332(83.4 \%)$ & $208(82.5 \%)$ & $0.425^{c}$ \\
\hline
\end{tabular}

It is also interesting to note that a significantly higher proportion of patients with poor BP control utilize calcium channel inhibitors and $\alpha$-receptor inhibitors (Table 4 ). In all, $52.3 \%$ of the patients were on aspirin, $56.8 \%$ on statins, $31.6 \%$ on diuretics, $46.4 \%$ on calcium channel inhibitors, $58.1 \%$ on $\beta$-antagonists and $70.8 \%$ were on either angiotensin-converting enzyme inhibitors or angiotensin receptor antagonists.

Finally, logistic regression analysis only identified two factors to be independently associated with good BP control, namely the male gender and the lower number of antihypertensives utilized (Table 6).

\section{DISCUSSION}

This analysis shows that there is significant gender difference in arterial hypertension control levels in Malaysia. The mean SBP was $6.9 \mathrm{~mm} \mathrm{Hg}$ higher in women, whereas the mean DBP showed no difference between the genders $(0.1 \mathrm{~mm} \mathrm{Hg}$ higher in men). This translated to a lower BP control rate in women of only $41.8 \%$ compared with $53.5 \%$ in men $(P<0.001$, Table 3$)$. This data mirror earlier data from NHANES (1999-2004), which showed a $4 \mathrm{~mm} \mathrm{Hg}$ higher SBP in women and the recently published I-SEARCH cohort, which showed a $2.1 \mathrm{~mm} \mathrm{Hg}$ higher mean SBP in women but no difference in DBP. ${ }^{8,13}$

Studies have shown that a $2 \mathrm{~mm} \mathrm{Hg}$ reduction in SBP is associated with a $7 \%$ reduction in IHD, IHD mortality and a $10 \%$ reduction in stroke mortality. ${ }^{14}$ Therefore, a $6.9 \mathrm{~mm} \mathrm{Hg}$ difference in mean SBP
Table 4 Percentage of hypertensive patients with good BP control within specific cardiovascular RF and antihypertensive subgroups

\begin{tabular}{lcccc}
\hline & $\begin{array}{c}\text { Total } \\
\text { sample, } \\
\mathrm{n}=950 \\
(e, \mathrm{n}=658)\end{array}$ & $\begin{array}{c}\text { Controlled } \\
\text { group, } \\
\mathrm{n}=461\end{array}$ & $\begin{array}{c}\text { Uncontrolled } \\
\text { group, }\end{array}$ & \\
& $(48.5 \%)$ & $(51.5 \%)$ & P-value \\
& $61.7 \pm 10.3^{\mathrm{b}}$ & $60.4 \pm 10.7^{\mathrm{b}}$ & $61.3 \pm 10.8^{\mathrm{b}}$ & $0.191^{\mathrm{c}}$ \\
& $138.8 \pm 20.3^{\mathrm{b}}$ & $123.1 \pm 9.4^{\mathrm{b}}$ & $153.7 \pm 16.2^{\mathrm{b}}$ & $<0.001^{\mathrm{c}}$ \\
Age (years) & $79.6 \pm 11.3^{\mathrm{b}}$ & $73.9 \pm 8.1^{\mathrm{b}}$ & $85.1 \pm 14.4^{\mathrm{b}}$ & $<0.001^{\mathrm{c}}$ \\
SBP (mm Hg) & $2.2 \pm 0.9^{\mathrm{b}}$ & $2.1 \pm 0.9^{\mathrm{b}}$ & $2.3 \pm 0.9^{\mathrm{b}}$ & $0.002^{\mathrm{c}}$ \\
DBP (mm Hg) & & & &
\end{tabular}

\section{Risk factor profile}

Diabetes mellitus $\quad 476(50.1 \%) \quad 90(18.9 \%)^{\mathrm{d}} 386(81.1 \%)^{\mathrm{d}}<0.001^{\mathrm{e}}$

Ischemic heart disease $519(54.6 \%) \quad 252(48.5 \%) \quad 267(51.5 \%) \quad 0.931^{\mathrm{e}}$

Revascularization $\quad 157(23.9 \%)^{\dagger} \quad 78(49.7 \%)^{\dagger} \quad 79(50.3 \%)^{\dagger} \quad 0.288^{e}$

Renal impairment $\quad 261(27.5 \%) \quad 48(18.4 \%)^{g} 213(81.6 \%)^{g}<0.001^{\mathrm{e}}$

Smoking $\quad 114(17.3 \%)^{f} \quad 51(44.7 \%)^{f} \quad 63(55.3 \%)^{f} \quad 0.821^{e}$

$\begin{array}{lllll}\text { Hyperlipidaemia } & 652(68.6 \%) & 318(48.7 \%) & 334(51.3 \%) & 0.915^{\mathrm{e}}\end{array}$

$\begin{array}{lcrrr}\text { Type of antihypertensive } & & & & \\ \beta \text {-Antagonist } & 552(58.1 \%) & 261(47.3 \%) & 291(52.7 \%) & 0.366^{\mathrm{e}} \\ \text { Diuretics } & 300(31.6 \%) & 132(44.0 \%) & 168(56.0 \%) & 0.058^{\mathrm{e}} \\ \text { ACEI/ARB } & 673(70.8 \%) & 322(47.8 \%) & 351(52.2 \%) & 0.513^{\mathrm{e}} \\ \text { CCB } & 441(46.4 \%) & 187(42.4 \%) & 254(57.6 \%) & <0.001^{\mathrm{e}} \\ \alpha \text {-Antagonist } & 50(5.3 \%) & 17(34.0 \%) & 33(66.0 \%) & 0.035^{\mathrm{e}}\end{array}$

Abbreviations: BP, blood pressure; DBP, diastolic BP; HTAA, Hospital Tengku Ampuan Afzan; HUKM, UKM Medical Center; RF, risk factor; SBP, systolic BP.

aControlled group $=\mathrm{BP}<140 / 90$, uncontrolled group $=\mathrm{BP} \geqslant 140 / 90$.

aControlled g
bMean \pm s.d.

${ }^{c} P$-value from independent sample $t$-test.

${ }^{d}$ Control level of $<130 / 80$ used in patients with diabetes.

e $P$-value from $\chi^{2}$ test.

fPercentage derived from two centers (HUKM and HTAA only).

${ }^{8}$ Control level of $<125 / 75$ used in patients with renal impairment.

Table 5 Percentage of hypertensive patients with good BP control within specific cardiovascular RF and comparison between genders

\begin{tabular}{lccr}
\hline Controlled BP & Males & Females & P-value \\
\hline RF profile & & & \\
Diabetes mellitus & $147(54.9 \%)$ & $85(40.9 \%)^{\mathrm{c}}$ & $0.002^{\mathrm{a}}$ \\
Ischemic heart disease & $185(53.3 \%)$ & $68(39.3 \%)$ & $0.002^{\mathrm{a}}$ \\
Renal impairment & $87(54.0 \%)$ & $41(40.6 \%)^{\mathrm{d}}$ & $0.023^{\mathrm{a}}$ \\
Smoking & $53(47.3 \%)$ & $2(20.0 \%)^{\mathrm{b}}$ & $0.089^{\mathrm{a}}$ \\
Hyperlipidemia & $216(54.4 \%)$ & $106(40.0 \%)$ & $<0.001^{\mathrm{a}}$ \\
\hline
\end{tabular}

Abbreviations: BP, blood pressure; HTAA, Hospital Tengku Ampuan Afzan; HUKM, UKM Medical Center; RF, risk factor.

a $P$-value from $\chi^{2}$ test.

bPercentage derived from two centers (HUKM and HTAA only).

'Control level of $<130 / 80$ used in patients with diabetes.

${ }^{\mathrm{d}}$ Control level of $<125 / 75$ used in patients with renal impairment.

between the genders translates to a 3.5-fold higher risk of IHD and stroke mortality for women in Malaysia. Furthermore, the gender difference in BP control is consistent across all participating centers (Figure 1), all cardiovascular risk factor groups (Figure 2) and in patients with between 1 and 4 antihypertensive medications (Figure 3).

When looking at the difference in SBP between men and women within the individual cardiovascular risk factor groups, the quantum seems to worsen, with the difference being $7.1 \mathrm{~mm} \mathrm{Hg}$ in those with diabetes mellitus, $8.5 \mathrm{~mm} \mathrm{Hg}$ in hyperlipidemics and $9.6 \mathrm{~mm} \mathrm{Hg}$ in 
Table 6 Logistic regression with univariate analysis showing only male gender and number of antihypertensives independently associated with good control status

\begin{tabular}{|c|c|c|c|c|c|c|c|c|}
\hline & \multicolumn{5}{|c|}{ Unadjusted } & \multicolumn{3}{|c|}{ Adjusted } \\
\hline & \multirow[b]{2}{*}{$\mathrm{N}$} & \multirow[b]{2}{*}{$O R$} & \multicolumn{2}{|c|}{$95 \% \mathrm{Cl}$} & \multirow[b]{2}{*}{$\mathrm{N}$} & \multirow[b]{2}{*}{ OR } & \multicolumn{2}{|c|}{$95 \% \mathrm{Cl}$} \\
\hline & & & $L L$ & $U L$ & & & $U L$ & $L L$ \\
\hline Gender (male) & 950 & 1.60 & 1.23 & 2.07 & 650 & 1.66 & 1.16 & 2.35 \\
\hline Age & 950 & 0.99 & 0.98 & 1.00 & 650 & 1.00 & 0.99 & 1.02 \\
\hline No. of antihypertensives & 939 & 0.80 & 0.70 & 0.92 & 650 & 0.73 & 0.61 & 0.88 \\
\hline Diabetic & 950 & 1.02 & 0.79 & 1.31 & 650 & 0.97 & 0.71 & 1.34 \\
\hline IHD & 950 & 1.01 & 0.78 & 1.31 & 650 & 1.13 & 0.77 & 1.67 \\
\hline Revascularization & 650 & 1.22 & 0.85 & 1.74 & 650 & 1.08 & 0.73 & 1.61 \\
\hline Renal failure & 933 & 1.02 & 0.76 & 1.35 & 650 & 1.16 & 0.78 & 1.72 \\
\hline Smoking & 650 & 0.96 & 0.64 & 1.42 & 650 & 0.80 & 0.53 & 1.23 \\
\hline Hyperlipidemia & 950 & 1.02 & 0.77 & 1.34 & 650 & 0.93 & 0.64 & 1.35 \\
\hline
\end{tabular}

Abbreviations: $\mathrm{Cl}$, confidence interval; IHD, ischemic heart disease; LL, lower limit; OR, odds ratio; UL, upper limit.

patients with renal impairment (Figure 2). This is compounded by the fact that only $18.9 \%$ of the patients with concomitant diabetes mellitus achieved the target BP of $<130 / 80 \mathrm{~mm} \mathrm{Hg}$ and only $18.4 \%$ of patients with renal impairment achieving the target BP of $<125 / 75 \mathrm{~mm} \mathrm{Hg}$ (Table 4). ${ }^{12}$ Furthermore, there was a statistically significant lower level of BP control in females across all cardiovascular risk subgroups (Table 5).

Data from NHANES and other large hypertension trials have also shown that most patients need combination therapy to achieve sufficient BP control, with most patients being on either two- or three-drug combinations and no differences were noted between the genders. ${ }^{15}$ Our study mirrors those findings with $41.4 \%$ of the patients on two-drug and $27.7 \%$ on three-drug combinations. Our data then depart from those prevailing trends by showing consistently higher mean SBP levels in women across all drug combination groups (Figure 3) before converging in the four- and five-drug combination groups. Our data also show that mean SBP increases with increasing number of drug combinations and age (Table 2 and Figure 3 ). This is confirmed by logistic regression analysis, which found that both a lower number of antihypertensive drug combination and male gender are independently associated with good BP control (Table 6).

There are several possible reasons for the difference in BP control and mean SBP levels. Firstly, more women are on single-drug therapy ( 26.2 vs. $21.0 \%$ in men), whereas more men are on two- or three-drug combination therapy (70.7 vs. $66.5 \%$ in women), which has been shown to result in greater hypertension control. ${ }^{16}$

Secondly, there are a significantly higher number of men with concomitant IHD (63.1 vs. $43.0 \%$ in women; $P<0.001$, Table 3 ), which may paradoxically result in greater hypertension control because of the greater number of medications prescribed, especially $\beta$-antagonists and angiotensin-converting enzyme inhibitors /angiotensin receptor antagonists. ${ }^{17}$ In our study, more men receive angiotensin-converting enzyme inhibitors or angiotensin receptor antagonists (72.6 vs. $68.4 \%$ in women, $P=0.09)$ and $\beta$-antagonists (62.4 vs. $52.2 \%$ in women, $P=0.001$ ). There is a statistically insignificant tendency to use more diuretics, calcium channel antagonists and $\alpha$-antagonists in women (Table 3 ).

Furthermore, because a higher percentage of men do have concomitant IHD, it may result in both clinicians and female patients underestimating their risk for developing IHD and stroke. This will, in turn, result in reduced recognition and less aggressive management of cardiovascular RFs in women. ${ }^{18,19}$ This is proven by the fact that a higher percentage of men are put on antiplatelet therapy (80.4 vs. $70.2 \%$ in women, $P=0.002$ ) and that only $13.9 \%$ of women with IHD actually undergo coronary revascularization (compared with $30.7 \%$ in men, $P<0.001$ ).

There are several limitations to this study. Firstly, our study did not take into account any different dosing strategies between the genders, despite there being data on differences in the way men and women metabolize drugs, respond or react adversely to them. ${ }^{20}$ Secondly, the cross-sectional and observational design of our study behooves that it is interpreted with caution. Finally, we had no data on the accuracy of BP measurements taken, the level of severity of concomitant illnesses in patients with multiple comorbidities and the level of education and socioeconomic status of our patients, all of which could impact on the accuracy of the data tabled here.

In summary, our data reveal a poorer BP control, secondary to higher SBP levels in women. We have also shown that although our data mirror recent studies highlighting differences between the genders in terms of BP control, the quantum is higher, thereby, necessitating more urgent intervention. Moreover, the gender difference in terms of mean SBP is more pronounced in patients with concomitant diabetes mellitus, renal impairment and IHD (Figure 2 and Table 5). In addition, although combination therapy was prescribed equally for both men and women, gender differences with regard to antihypertensive drug classes prescribed occur. This study illustrates the urgent need for quality improvement efforts among physicians and policy makers for all patients with hypertension, especially women.

1 Whitworth JA, World Health Organization, International Society of Hypertension Writing Group. 2003 World Health Organization (WHO)/International Society of Hypertension (ISH) statement on management of hypertension. J Hypertens 2003; 21: 1983-1992.

2 Lim TO, Morad Z, Hypertension Study Group. Prevalence, awareness, treatment and control of hypertension in the Malaysian adult population: results from the national health and morbidity survey. Singapore Med J 1996; 45: 20-27.

3 Ministry of Health Malaysia. The Third National Health and Morbidity Survey; Hypertension (online). (Accessed May 18, 2010, at http://www.nih.gov.my/NHMS/abstracts_18.html).

4 Kearney PM, Whelton M, Reynolds K, Muntner P, Whelton PK, He J. Global burden of hypertension: analysis of worldwide data. Lancet 2005; 365: 217-223.

5 Cutler JA, Sorlie PD, Wolz M, Thom T, Fields LE, Roccella EJ. Trends in hypertension prevalence, awareness, treatment, and control rates in United States adults between 1988-1994 and 1999-2004. Hypertension 2008; 52: 818-827.

6 Turnbull F, Woodward M, Anna V. Effectiveness of blood pressure lowering: evidencebased comparisons between men and women. Expert Rev Cardiovasc Ther 2010; 8: 199-209.

7 Turnbull F, Woodward M, Neal B, Barzi F, Ninomiya T, Chalmers J, Perkovic V, Li N, MacMahon S. Do men and women respond differently to blood pressure-lowering treatment? Results of prospectively designed overviews of randomized trials. Eur Heart J 2008; 29: 2669-2680.

8 Thoenes M, Neuberger HR, Volpe M, Khan BV, Kirch W, Böhm M. Antihypertensive drug therapy and blood pressure control in men and women: an international perspective. J Hum Hypertens 2010; 24: 336-344.

9 Lloyd-Jones DM, Evans JC, Levy D. Hypertension in adults across the age spectrum: current outcomes and control in the community. JAMA 2005; 294: 466-472.

$10 \mathrm{Kim}$ C, Redberg RF, Pavlic T, Eagle KA. A systematic review of gender differences in mortality after coronary artery bypass graft surgery and percutaneous coronary interventions. Clin Cardiol 2007; 30: 491-495.

11 Lip GY, Butt M. Gender and the response to blood pressure-lowering treatment. Eur Heart J 2008; 29: 2585-2586.

12 Chobanian AV, Bakris GL, Black HR, Cushman WC, Green LA, Izzo Jr JL, Jones DW, Materson BJ, Oparil S, Wright Jr JT, Roccella EJ. The seventh report of the Joint National Committee on Prevention, Detection, Evaluation, and Treatment of High Blood Pressure: the JNC 7 report. JAMA 2003; 289: 2560-2572.

13 Ong KL, Tso AWK, Lam KSL, Cheung BMY. Gender difference in blood pressure control and cardiovascular risk factors in Americans with diagnosed hypertension. Hypertension 2008; 51: 1142-1148. 
14 Lewington S, Clarke R, Qizilbash N, Peto R, Collins R, Prospective Studies Collaboration. Age-specific relevance of usual blood pressure to vascular mortality: a metaanalysis of individual data for one million adults in 61 prospective studies. Lancet 2002; 360: 1901-1903.

$15 \mathrm{Gu} \mathrm{Q}$, Burt VL, Paulose-Ram R, Dillon CF. Gender differences in hypertension treatment, drug utilization patterns, and blood pressure control among US adults with hypertension: data from the National Health and Nutrition Examination Survey 1999-2004. Am J Hypertens 2008; 21: 789-798.

16 Mancia G, Grassi G. Systolic and diastolic blood pressure control in antihypertensive drug trials. J Hypertens 2002; 20: 1461-1464.
17 Keyhani S, Scobie JV, Hebert P, McLaughlin MA. Gender disparities in blood pressure control and cardiovascular care in a national sample of ambulatory care visits. Hypertension 2008; 51: 1149-1155.

18 Mosca L, Mochari H, Christian A, Berra K, Taubert K, Mills T, Burdick KA, Simpson SL. National study of women's awareness, preventive action, and barriers to cardiovascular health. Circulation 2006; 113: 525-534.

19 Mosca L, Linfante AH, Benjamin EJ, Berra K, Taubert K, Mills T, Burdick KA, Simpson SL. National study of physician awareness and adherence to cardiovascular disease prevention guidelines. Circulation 2005; 111: 499-510.

20 Taler SJ. Hypertension in women. Curr Hypertens Rep 2009; 11: 23-28. 